\title{
APRESENTAÇÃO GÊNERO E SEXUALIDADES: DISSIDÊNCIAS E RESPIRAÇÕES
}

\author{
Ana Luísa Amaral ${ }^{1}$ \\ Emerson Inácio ${ }^{2}$ \\ Paulo César García ${ }^{3}$
}

já que sabemos tod@s que, porra, o ser é com perucas, que não ontologias.

Horácio Costa, "Projeto para uma revolução urbana em Goiânia ou: o Ser é com Perucas"

$[\ldots]$ as suas famosas palavras foram não consigo respirar então, se somos nós sempre a ameaça para quem para onde nos havemos de voltar, pedindo protecção?

Pamela Sneed, “I can't breathe”, 2020

Em tempos tão nevrálgicos como estes por que passamos, em meio a ameaças de novas ditaduras, do ressurgimento desavergonhado da supremacia branca, do sexismo, da homofobia, da transfobia, acompanhados no último ano pela pandemia que fez alargar de forma alarmante o fosso entre ricos e pobres, mais urgente que nunca se afigura falar em dissidências. Porque dissidência significa dissonância, desobediência, o oposto de aquiescência e de submissão.

Falar em corpos dissidentes é dar visibilidade ao que desafia uma dada estrutura cultural e social que só aparentemente é hegemônica e é

\footnotetext{
${ }^{1}$ Ana Luísa Amaral é Professora Associada aposentada do Departamento de Estudos Anglo-Americanos da Faculdade de Letras do Porto, atualmente, é investigadora na Faculdade de Letras do Porto e membro da Direção do Instituto de Literatura Comparada Margarida Losa. E-mail: analuisaamaral@netcabo.pt.

${ }^{2}$ Emerson da Cruz Inácio é Doutor em Letras em Literatura Portuguesa pela Universidade Federal do Rio de Janeiro (2006), tendo sido orientado pelo Prof. Dr. Jorge Fernandes da Silveira. Desde 2006 atua na Faculdade de Filosofia, Letras e Ciências Humanas da Universidade de São Paulo. E-mail: einacio@usp.br. ${ }_{3}^{3}$ Paulo César Souza García é Doutor em Literatura e Professor Titular Pleno da Universidade do Estado da Bahia. E-mail: pgarcia@uneb.br.
} 
oferecer essa visibilidade através do meio que a tod@s é comum, simultaneamente letal e emancipador: a palavra. É que produzir linguagem implica preencher um mundo de sentidos. Como fez notar Toni Morrison, na sua bela intervenção aquando da atribuição do Prémio Nobel em Literatura, em 1993,

a linguagem opressora faz mais do que representar a violência; ela é violência. Faz mais do que representar os limites do saber; ela limita o saber. Quer seja a obscura linguagem usada pelos governos ou a falsa linguagem de alguns meios de comunicação; quer seja a linguagem arrogante e calcificada da academia ou a linguagem obcecada com o empreendedorismo de alguma ciência; quer seja a linguagem da lei-sem-ética, ou a linguagem pensada para a alienação das minorias, que esconde o seu viés discriminatório por detrás do literário - essa linguagem deve ser rejeitada, alterada, denunciada.

Os gestos que fazemos, as palavras que dizemos têm consequências. Quando se dá a falha radical do pensamento, a perda, pelo esquecimento induzido ou por nós voluvelmente aceito, da capacidade humana da escolha da liberdade - dá-se de fato a fuga da responsabilidade. A mediocridade devese à falta de crença na imaginação, à perda da capacidade para duvidarmos e nos interrogarmos.

Acreditamos que um dos caminhos para combater o estado atual das coisas é recusar habitar e praticar os roteiros que nos foram impostos e que fomos interiorizando. É admitir que pelo silêncio nos tornamos cúmplices da violência de que fala Morrison, e que se estende da palavra a outros domínios: o jurídico, o escolar, o religioso. Uma das formas de luta que podemos travar, nós, que lidamos com a palavra, reside em criar poéticas de resistência que acomodem políticas sexuais e combatam a exclusão. Fazer uma poética da resistência significa fazer política social. Porque fazer política social é fazer política contra a exclusão e fazer política contra a exclusão é fazer política sexual.

Por que este ódio às sexualidades dissidentes, perguntamos? Porque este ódio à teoria queer, como ficou patente no ataque a Judith Butler em 2017, em frente ao SESC Pompeia, em São Paulo? Por que este ódio aos corpos que se 
não ajustam a uma suposta "normalidade"? Para podermos melhor refletir sobre isso teremos de pensar nos feminismos. É que o ódio não se dirige só à teoria "esquisita", mas ao "esquisito" que é as mulheres terem há pouco mais de um século desafiado abertamente o binarismo, a separação entre o público e o privado, os papéis de gênero, em suma. Concomitantemente, aquel@s que têm vindo a reivindicar o direito à sexualidades outras, debatem-se com a heteronormatividade homofóbica e mesmo com uma ordem homossexual estandardizada, que exclui as formas menos padronizadas e até lúdicas ou artísticas de condutas sexuais. Assim se consideram duplamente "estranh@s" @s drag queens, @s transsexuais, @s travestis, @s pansexuais. Ora, a desconstrução das identidades fixas e das práticas normalizadoras dos sistemas de dominação deveriam ter como objetivo criar condições para que tod@s, sem exceção, pudessem ter a possibilidade real de viver a vida que escolheram, no âmbito de uma filosofia da liberdade.

Tal como as mulheres no início do século XX se uniram a sindicatos ou a associações de trabalhadores, interessaria agora construir novas políticas de coligação. Butler sempre tentou dar uma resposta, desde o seu Gender Trouble [Problemas de Gênero] (1990) até Notes Toward a Performative Theory of Assembly (2015), ao conceito de coligação, em termos teóricos e políticos, prefigurada pela teoria queer, afirmando que as linhas a seguir são convites ao cruzamento de fronteiras e sublinhando a importância do reconhecimento da vulnerabilidade e da precariedade que apontam para uma teoria social do corpo-em-sociedade, em termos de interdependência. Todos os corpos e qualquer corpo. Tal proposta só será exequível, no entanto, pela aliança entre todos os vetores de dominação, que poderá assumir a forma não de um campo teórico uniforme e uniformizado, mas de um conjunto de "formas de teorização "queer" (HALL, 2003, p. 5), plurais, baseadas "no estabelecimento de elos de ligação entre grupos diversos" (HALL, 2003, p. 5).

Diferentemente de Gayatri Spivak e do seu conceito de "essencialismo estratégico" (1988), que se baseava, ainda que em termos culturais e não antropológicos, na unidade, estas seriam coligações abertas, baseadas na afirmação de "identidades que são alternativamente instituídas ou abandonadas de acordo com os objetivos a atingir" (BUTLER, 1990; HALL, 2003). Este tipo de política permitiria pactos baseados numa intersecção de 
interesses e possibilitaria a subversão da norma instituída pelo poder hegemónico, gerando novos vetores de possibilidades. Novas formas de poder.

Em Spinoza for Our Time: Politics and Postmodernity (2013), Antonio Negri retém a distinção feita por Espinosa, e já por Negri identificada em Savage Anomaly (1981), entre dois sentidos de poder: potentia ("potência") - a essência constitutiva de um ser vivo que deseja o que é bom para a sua existência - e potestas ("poder"), o poder transcendente de comando assumido e exercido pelos governantes. Potentia oferece-nos o potencial de sermos livres e de nos juntarmos a coletivos compostos por aqueles com quem partilhamos uma natureza comum. Por seu lado, "potestas" (o outro tipo de poder) pode permitir e até encorajar a potência ou pode ser usado para a suprimir. Diversamente de conceitos políticos ligados à ideia de poder que se limitam a rearranjar o aparelho ligado à soberania e à lei, o conceito ontológico de potentia permite, assim, uma democracia a ser continua e coletivamente constituída.

O novo milênio parecia mostrar, como dizia Boaventura de Sousa Santos (2001), que o global poderia ser sinônimo tanto de fatalidade, como de utopia, parecia antever um século de extremadas desigualdades, mas também da coexistência de múltiplos discursos, apontando, pelo menos potencialmente, para a possibilidade de pertença a vários espaços simultaneamente, ao convidar à mestiçagem do pensamento como propunha Gloria Andalzua, ainda em 1997, no seu Borderlands. Em suma, parecia permitir expandir "a nossa capacidade de imaginar o humano" (BUTLER, 2004, p. 228), de forma a trabalhar conjuntamente por uma sociedade menos injusta e mais inclusiva.

É tudo isto que acabamos de dizer que hoje parece estar em risco; por isso se afigurou para nós absolutamente essencial um número como este de uma revista que tem por núcleo aglutinador o título genérico Ponto de Interrogação. investigar como os novos sujeitos estreitam análises de natureza significativas ou são nelas representados; estudar formas de ser que desafiem as conformidades culturais e literárias canônicas e que ofereçam espaço a expressividades estéticas que respondam à efetiva fluidez dos corpos, das novas subjetividades e das novas identidades. 
Os treze ensaios que se seguem são de natureza interseccional e distribuem-se entre preocupações que cruzam o gênero e a raça com sexualidades, tendo sempre como objeto a cultura ou a literatura e como pano de fundo as ferramentas teóricas quer dos Estudos Feministas, quer dos Estudos Gay e Lésbicos, quer da Teoria queer. Assim, os ensaios, como o que introduz o periódico Sexualidad en La Infancia em las Memorias de Salvador Novo Y Elías Nandino, de Maurício List tem a pertinência crítica e analítica, quando retrata sobre a sexualidade na infância, abordando a memória de Salvador Novo e Elías Nandino; o ensaio SIDA e homossexualidade em Última paragem Massamá, de Monalisa Almeida Cesetti Gomyde, que explora a função metafórica, ética e estética da SIDA num romance de Pedro Vieira. Chame-se também a atenção para ensaios de dimensão interartística, como o de Djalma Thürler e Duda Woyda, tratando d' O equilíbrio precário entre arte e realidade: em Abel Azcona, que cruza teatro, corpo e colonialidade, mostrando as infiltrações da performance no teatro contemporâneo; ou o ensaio de Leonardo da Silva 'I'm not afraid of being called a loser': the issue of agency in Finn's identity construction in the television series Glee, que se debruça, a partir de uma série televisiva, sobre a questão da ambiguidade na construção da identidade pessoal e do agenciamento. A relevância do texto de Wilken Figueredo Matos e Marcus Antônio Assis Lima, Laerte, Muriel e a Autobiotransimagem, que é dedicado às histórias em quadrinhos e à experiência trans na pessoa da brasileira trans Laerte Coutinho.

Registre-se ainda a leitura queer da poesia que nos é trazida por Maximiliano Torres, em Pedagogias de ser: escuta e visibilidade de corpos em Antologias Trans e igualmente ensaios que se debruçam sobre a questão da masculinidade hegemônica e outros diferenciais, como a classe ou a idade, como dar a ler o ensaio O Corpo-Prostituto nos contos de Gasparino Damata, de Dorinaldo dos Santos Nascimento ou ainda o ensaio Feminism and dissident femininity in popular culture. Cher's role and the role of religion in Moonstruck, da autoria de Orquídea Cadilhe, que se dedica a uma análise da desmontagem dos papéis sexuais pela figura de Cher.

Quanto aos textos de Mariana Alves da Silva e Helder Thiago Maia em Gênero, Sexualidade e Nação: a Rainha Ginga entre o Esquecimento e a Invenção do Mundo e de Camila de Matos Silva em (Re)pensando a respeito 
das narrativas de viagem "tradicionais" - diáspora como formação do sujeito transcultural em Um defeito de cor, centram-se no cruzamento entre gênero e raça, ora mostrando a necessidade de repensar o cânone da chamada Literatura de Viagens, ora infletindo nos conceitos de nação e identidade nacional; também, considere o trabalho em torno das estratégias de escrita na obra de autores da chamada literatura gay, como o texto De afetos românticos a performances neonaturalistas: uma reflexão sobre práticas homoafetivas na literatura de língua portuguesa, de Antônio de Pádua Dias da Silva.

O nosso número do Dossiê conta também com ensaios dedicados à poesia, como a análise de Ricardo Alves dos Santos revelada em $O$ contexto, $o$ social e a questão do sujeito lírico em Glauco Mattoso, que faz confluir sexualidade, doença e poesia marginal. Por fim, refira-se ao ensaio de Marcelo de Trói e Susana Batel, ao expor a Cidade straight versus cidade dissidente: a street art como demarcação do lugar em Lisboa, dedicado às topografias dissidentes, um estudo, na cidade de Lisboa, da chamada street art, enquanto expressão ativista.

Fechando este volume, temos uma resenha, um poema e um entrevista. A belíssima resenha de Rafael Mérida aponta com pensamento crítico a incisiva exposição trans Cabello/Carceller. Borrador para una exposición sin título, que teve lugar entre Fevereiro e Maio de 2019, no Museo Universitario de Arte Contemporáneo da Universidade Nacional Autónima de Mexico. Nos tempos escuros / Haverá também canções? Sim, haverá também canções / Sobre os tempos escuros, escreveu Bertold Brecht, em 1939. Talvez, o lugar de onde melhor se possa falar de dissidências seja a poesia; faz por isso todo o sentido que uma das últimas contribuições deste número seja um extraordinário poema de Horácio Costa: Projeto para uma Revolução Urbana em Goiânia, Ou: O Ser é com Perucas, de onde selecionamos o excerto que, aqui, usamos como epígrafe desta apresentação do dossiê. Propondo uma "revolução urbana", o poema tece uma teia, ao mesmo tempo cerrada e fluida, de referências literárias e culturais que vão desde Virginia Woof ao filme Priscilla, Queen of the Desert, passando por Artaud ou Robbe-Grillet, para delas se apropriar ou as parodiar. É um poema de resistência poderosíssimo, este com que Horácio Costa honra o volume e, através dele, denuncia, em gesto de sabotagem lírica, os nossos tempos. É, por isso, um amplíssimo 
poema que respira - e nos ensina como a poesia pode, apesar de tudo, ensinar novas respirações.

Encerra o número a que chamamos "Gêneros e sexualidades dissidentes na literatura e na cultura" uma entrevista a Mário César Lugarinho, conduzida por Paulo César García, sob a inspiração de Ativismo social, político e cultural: entre histórias, corpos, pensamentos... que é de fato uma viagem extremamente original pela história dos movimentos Lgbtqi+, da sua entrada na academia enquanto objeto e áreas de estudo e reflexão, da consolidação da teoria queer, dos estudos trans e da crescente visibilidade dos corpos dissidentes. Lugarinho recorda como na virada do nosso século (há escassos 20 anos, pois), "discussões que avançassem para o estudo das identidades configuradas pela raça e etnia ou pelo gênero ainda eram muito questionadas, criticadas e, muitas vezes, invalidadas", mostrando como a mudança foi o resultado de um esforço conjunto da academia e do ativismo. A entrevista contempla ainda uma interessante reflexão sobre o percurso levado a cabo pelo cruzamento entre os Estudos Gay e Lésbicos e as Literaturas Africanas de Língua Portuguesa, apontando obras que se encaixam como dissidentes e assumem a problemática das identidades sexuais.

Portanto, o segundo volume 10, n. 2 da Revista Pontos de Interrogação apresenta um significativo objetivo: elencar produções textuais, de viés crítico-analítico - com destaque para a crítica literária e cultural demonstradas pelo pensamento de autoras e de autores acerca da emergência de novos sujeitos. Pretendeu-se com isso recepcionar textos com questões instigantes que oferecessem expressividades mobilizadas pelas identidades fluidas e interseccionais e cujos enunciados considerassem formas dissidentes, dentro do contexto do horizonte cuir. Assim o Dossiê Gêneros e Sexualidades Dissidentes na Literatura e na Cultura proporciona eletivos debates oriundos das ligações temáticas peculiares a cada autoria e com a propriedade de investigação baseada na expressividade estética que diz sobre diversos modos de ver e de interpretar outras formas de existir. Certos estamos de que, também, os textos nos oferecem leituras em estado de resistências às conformações culturais canônicas e/ou desviadas das formas hegemônicas impostas pelas artes em geral e pela literatura, em particular. 


\section{Referencias}

ANDALZUA, Gloria E. Borderlands, La frontera/ La new mestiza. San Francisco: Aunt Lute Books, 1987.

BUTLER, Judith. Problemas de Gênero. Rio de Janeiro: Civilização Brasileira, 2003. [Gender Trouble: Feminism and the Subversion of Identity. New York: Routledge, 1990.].

BUTLER, Judith, Undoing Gender. London \& New York: Routledge, 2004.

BUTLER, Judith. Notes Toward a Performative Theory of Assembly. Cambridge, Massachusetts: Harvard University Press, 2015.

HALL, Donald. Queer Theories. London: Macmillan, 2003.

Morrison, Toni (1993), “Nobel Speech” (1993). Disponível em: https://www.nobelprize. org/prizes/literature/1993/morrison/lecture/. Acesso em: 14 dez. 2020.

NEGRI, Antonio Negri. Spinoza for Our Time: Politics and Postmodernity. New York: Columbia University Press, 2013.

NEGRI, Antoni. Savage Anomaly: The Power of Spinoza's Metaphysics and Politics. Minneapolis: University of Minnesota Press, 1981.

SANTOS, Boaventura de Sousa. Globalização: Fatalidade ou Utopia? PortoPortugal: Edições Afrontamento, 2001.

SPIVAK, Gayatri Chakravorty. Pode o subalterno falar. Belo Horizonte: Editora UFMG, 2010. [Spivak, Gayatri Chakravorty. "Can the Subaltern Speak?", Nelson, Cary; Grossberg, Lawrence (eds.). Marxism and the Interpretation of Culture. Basingstoke: Macmillan, 1988. p. 271-313]. 